\title{
What are the Predictors of Performance Evaluation? (Evidence from Colleges of Punjab Pakistan)
}

\author{
Rahman-ul-Islam, Atif Mahmood, Muhammed Nawaz, Muhammad Irfan \\ Shakoor \\ MS Scholars, Department of Management Sciences \\ The Islamia University of Bahawalpur, Pakistan
}

\begin{abstract}
Organization cannot be run only with machines and ignoring the human resource. Human resource performance can be stimulated with the training and development programs in the organization. Humans can learn from Training and development programs but they are accountable to the organization through performance evaluation process conducted by the organization. Many researches have been conducted on performance evaluation but this study fulfills the gaps which exist in previous literatures. No doubt performance evaluation make accountable to the employees in front of their organization but it is beneficial for them because after evaluation process efficient and talented employees are promoted and there fringe benefits may move towards increment. As for as organization is concerned, due to performance evaluation process organization productivity increases. This study used five exogenous variables named as ADO, AT, TD, TT, FS and endogenous variables such as performance evaluation. This research investigated the relationship of independent variables and dependent variables. Therefore it is concluded that four variables such as ADO, AT, $T D$, FS have significant positive association with performance evaluation while TT has insignificant positive relationship. The concept of transfer of training is not used more in Pakistan.
\end{abstract}

Keywords: Performance Evaluation, Colleges teachers, Regression, Collinearity, Pakistan

\section{Introduction}

Education is the earliest persuasion of a Muslim. The Holy Prophet (PBUH) directed the substance of education when he said the Muslims to get acquaintance even if they had to go to China. Learning is the direction for all human and enable to people for any decision in life with their mind and understanding. Appraisal develops a precious prospect to focus on work activities and goals to discover with correcting current problems. Performance evaluation identifies the employee that every organization in fact measure individual performance of worker. Performance appraisal is the responsibility of HRM department and all organization has their own department. Performance Appraisal provides the actual performance of employee and due to this all employee fulfills their responsibility.

Organizations evaluate the performance after specific period of time and this evaluation process completed through from seniors because they well aware about the performance of subordinate. If senior evaluated performance of subordinates wrong than results not matched with actual performance of employee. After performance evaluation of employees a supervisor can design training for further development. Training and development programs are obligatory for teachers. In this world no one can achieve their goal without any guidance. Transfer of training also impact on performance appraisal of teacher because after training and development the implementation is hurdle. Each employee should receive a considerable and perfect appraisal. The achievement of evaluation process depends on the supervisor's compliance to complete a productive and intent appraisal and also on the employees' readiness to retort to helpful ideas reach future goals.

The successful achievement is taken from vision mission and goals of any organization. Performance evaluation system provides records of actual and past performance of employee separately after that organization reconciles the results of appraisal. It is a set of activities through work, target are identified and then give rewards to their employee of organization. Due to performance evaluation system productivity also enhance, organization objectives always in front of them such as, the definition of performance evaluation in Oxford Advanced Learner's Dictionary "A judgment of the value or nature of somebody". A meeting in which senior authorities discuss with their employees that how they are doing their job. Business Definition for performance appraisal is to seeking the measurement of employee work effectiveness using objective criteria. Appraisal system is a process that evaluates performance of employee of organization continuously; it should not only for one or two year formally. This system depends on organization objectives and also employees that how much this system requires for employees and organization.

Different organizations use different methods during their performance evaluation process. Why performance evaluation process is conducted in the organization? Organizations perform this process to access 
the competencies and weaknesses of the employees and finally, to bring new methods for improving the employees performance as well. When evolution process is completed suitable assistance is provided to the employees to upgrade their information. Different predictors are used in performance evaluation process by different institution.

Many researchers have used attendance of teacher's suitable exogenous variables for performance emulation. They are of the view point that when teacher are most obedient with their presence in their institution their performance goes high. On contrary, those teachers who cannot perform as well they are caused by their more absence in their institution. Training and development is also consider much important factor for analyzing somebody performance in their job tasks. A lot of human resources exports evaluate the performance of their employees during training and development programs. They think that those employees who have craze for more and more trainings for them and they are considering best performers in the organization because they want growth in their careers.

Problems start at that time when employees do not work even after getting trainings, this phenomenon known as transfer of training. These employees do not take more serious to the trainings contents what they have learnt in their trainings and do not try to apply these learning on their actual jobs. Therefore, when performance evaluator uses transfer of training as predictor of performance evaluation he takes into consideration his current performance on job tasks after training. If he is following the trainings it is considered good performer otherwise he is not. As for as Pakistan is concerned, the transfer of training is not so effective in the organization employees learn from training but do not apply it on job tasks.

\section{Literature Review}

The quality of education depends on the high performance of the teachers. And the teacher's performance can be enhanced by their evaluation. As David and Macayan (2010) explained that teachers effectiveness can be judged through accountability, this is the process by which it can be measured that what the teachers are doing and it is according to the standards or not.

Similarly Clouse (n/d) stated for evaluation purpose the private institutions can be hired or the subject specialists can be hired for this purpose as they have the better knowledge about the subject so they will better evaluate the performance of the teachers of the specific subject. It improves the quality of knowledge that is necessary for classroom instruction; it contributes better achievement of goals and desired results for school and colleges.

Jahangir (1988) explained in the study of Pakistan, he gave the different levels to the teachers according to their behaviors, teaching, techniques, physical features and objectives. The

main objective to study about teacher act of teaching according to postgraduate level, the entire evaluation based on 70 students of Peshawar University to evaluate the teacher performance but according to his study that the result was that students were giving the point to their teacher on the base of their personality and on the base of their most like teacher either on the behalf of their impressive teaching or effective manners. It would main possible reason for satisfactory student teacher interaction.

Aslam et al (2008) examined that performance appraisal of teacher was treated by majority only for promotion purposes, as the result showed in their survey about $74 \%$ of selected teachers are believed that it was for promotion. Their results concluded that there is a communiqué gap among teachers and administrator, which showed the performance, was poor because the teachers had lack of trust, but the teacher must have consecutively to build up a good performance assessment system.

Marshall (2009) explained the different changes will occur because of continuous learning of teachers, there will be communication between teachers and the principal about the evaluation process and they will try to overcome their weaknesses and takes responsibility to improve their own teaching. It can help to progress employee's job performance by identifying strengths and weaknesses and conclude how their strengths can be best utilized for the success of organization.

Sadker and Sadler (1997) observed that the teacher who are efficient they engaged most of their time in class room activity related to studies and before coming to college or class room, they remained preplanned about their subjects and duties and those engaged students in class room activity also involve them in creative activity, also they put questions on students according to their caliber for taking out their mental level, also they encourage them and their interest and build class room as two way communication with knowledgeable environment.

Iqbal (1986) conducted study and putting questions and taking answers by almost 150 teachers and 50 head of different institute to know about the individual teacher's personality and their prominent skills. Therefore he found that majority of teachers had such quality like punctuality, hard worker and sincere with their profession seriously. Darling \& Hammond (2000) argued that teachers who have had more training for teaching are more self-assured and unbeaten with students than those who have had little or none. In addition, the Darling \&Hammond stated that the programs with extensive systematic preparation interweave with the coursework during erudition and teaching generate teachers are more effective. Stay in teaching (2000, p.166) 
There are different methods used to evaluate the performance of employees all over the world. Anglicitina (2004) stated that these are MBO method and Total Quality Management Approach. MBO method of performance appraisal triumph over some of the problems that arise when assuming that the employee traits needed for job success can be reliably recognized and considered. Instead of assuming traits because it focuses on actual outcomes and gives a satisfying sense of autonomy and achievement to employees.

From a Total quality management (TQM) perspective, conventional performance review can probably affect quality and joint effort, because it makes employees try to win against one another. Solution might be ranking teams rather than folks. There are different approaches for the evaluation of teachers and different methods are being used for this purpose. As Marshall (2009) stated that the principal can take mini observations, can do curriculum planning, interim assessment and end of year evaluation of teachers. In mini observations a visit to the class is done without informing the teacher, an curriculum planning the main purpose of the topic will be assessed that teacher have knowledge about it or not, in interim assessment the performance is being assessed interim by working with employees in teams and in end of year evaluation of employees.

If an educational institution has an effective evaluation system then it plays very important role for the development of employees and it leads institution towards the progress. Similarly Goe et al (2008) stated that effectiveness in performance consists on effective teachers have high expectations from students, contribute in providing the positive academic, self efficacy and cooperative behavior, better communicate with teachers, administrators, parents and other professionals. Anderson (2004) suggested that an effective college teacher is who tries to achieve his goal by focusing on the students learning, he must have basic command on his subject and have ability to communicate his knowledge effectively. Sadker (1997) founded that efficient teachers know their subject matter, structured it and fritter key part of the class time on academic actions, structure learning experiences carefully clearly present both guidelines, content information and asked both higher and lower level questions as fitting to objectives of the lesson.

The other factors affecting the performance of teachers are lack of training, work overburden, strict evaluation, classroom discipline problems, misbehavior of students, lack of communication, least progress opportunities in teaching field. Sarwar et al. (2010) asserted that there is lack of proper training programs for teachers and no opportunities are given to them for further development and career making in teaching field. Moreover in colleges the classroom discipline and misbehavior of students also affects the teacher's performance.

The Boston public school feels that the quality of education depends on the performance of teacher and how affect performance of teacher. So system should be appropriate that fulfill the entire performance level, right performance evaluation system provide actual strength and weakness of teacher. An appraisal system is better that enhance the performance of teacher gradually. Due to this Boston public school develop professional staff and gives clear understanding for assessing performance of teacher.

In 1999, Oregon university system and the Oregon public employee union introduced new program for employees who working in information technology system, this was introduced for check and balance of employees because it supports and promotes organizational effectiveness through increased productivity at individual and group level. Beerens (2000) explained the causes of evaluation process are effectiveness, promotion growth and reduce the weaknesses of teachers. For this purpose teacher's evaluation is closely related to functions such as serving the teacher to progress (influential evaluation) and shaping the future employment status of the teacher (summative). The expansion and improvement function of evaluation (formative) is repeatedly observed in antagonism with the responsibility function (collective). In fact teacher's evaluation systems have been habitually driven by the concerns.

The teacher's performance can be evaluated through the performance of their students. Theall and Franklin (2001) argued that there is high relation between students rating and the teacher's performance. Teaching effectiveness can be judged in terms of student's productivity.

Shah and Sultana (1997) argued that teacher training has great impact on their performance, teacher's education has newly acquired great value in our national education structure because it has increasingly been realized that the quality of secondary education can be improved with teachers who have received proper worth training in our institute of teacher education. According to Beerens (2000) teacher's evaluation must include teacher self evaluation, peer coaching and peer observations. Teachers should be free from the fear of the negative assessment but they are interested or readily to boost the quality of their professions.

Helsel, Aurbach and Willower (1969) showed that individual teachers thought related to college system had big relation with their thought to change education individual's perceptions of the principal's consideration, thrust and production importance were openly hopefulness of prospects. But it also related to teacher point of view that change in principal put great change which will be a successful desired change rather that change in behaviors of teachers. George and Bishop (1971) also argued that performance evaluation scale scores indicated that teacher's perceptions of college system were related to the combined effects of perceived educational structure and individual personalities. 
Lower (1987) asserted that many teacher recognize teacher's evaluation as purposeless, biased, unreliable and too subjective. The principles and the practices are shoddy. Desseler (1982) stated that job satisfaction and performance have close relationship. If the person is satisfied from his job than his performance will be good but if he is not satisfied than he will not perform well. Teacher's personality also contributes in performance. According to Gage (1983) the teacher's behavior is consider to be a reflection of his personality. Personality qualities are sample of all behaviors. Intelligence, knowledge of subject and authority are the examples of dimension of the personality of the teachers. Similarly Zehm and Kottler (1993) explained that the personalprofessional proportions make teachers great. The great teachers had great personality.

Srivastava (1985) asserted that teacher and principal's relation with college system that the teachers usually perceived the system of their institution to be closed whereas principal supposed it to be open. Casteed (1995) measured the relationship between the different aspect with related to college environment and results concluded that there is much more difference between the thought of principal and teacher, increased by scoring. A study by Johan \& Taylor (1999) expressed that there is relationship among the principal style, college environment and institutional agreement with teacher this data were obtained by the 227 teacher from 20 colleges. He showed that these things are inter-correlated. They also cleared that teacher commitment has positive relation with college environment; it relates to open type studied environment, principal positive attitude and teacher involvement play an important role in open environment. They also explained that positive leadership behavior or positive techniques to handle the situation is useful for the good environment of colleges. Johnsrud, et al. (2000) focused on the spirits of middle level administrator. significant morale as "a state of mind regarding one's job, including commitment, satisfaction, sense of common plus loyalty intention with respect to one's work", he also pointed out that college environment also related to some morale values and some specific tips which help for successful of environment, like appreciation deep sense for purpose of job and best leadership. Volkwein (2003) argued that the satisfaction of job or durability of job related to administrative principal at both private and public universities, in which he studied that why job come on risk what is the circumstances which make any job dissatisfactory, like insecure features, work on the tension of supervision, impose pressure which make environment stressful, all these things creates negative impression to carry on job for long period. Whereas the opposite of these like freely environment and freedom choices other subjects teacher and principal coordination, good relationship between colleagues has positive impact on the satisfaction of job.

\section{Hypothesis development}

The researchers developed following hypothesis for five variables based on previous literature.

H1: There is a momentous positive correlation between ADO and PE.

H2: There exists a considerable positive connection with AT and PE.

H3: There is a significant positive liaison between TD and PE.

H4: There exist a noteworthy positive link with TT and PE.

H5: There is a significant positive relationship among FS with PE.

\section{Research Model}

The Determinants of Performance Evaluation

Five variables are used for performance evaluation of teachers in private and public colleges.

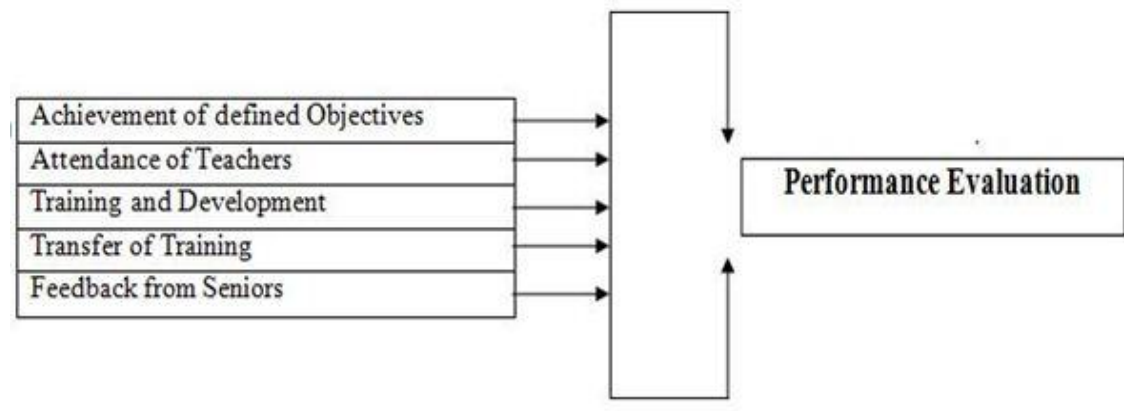

Abbreviations Table

\begin{tabular}{|l|l|l|l|}
\hline Performance Evaluation & PE & Transfer of Training & TT \\
\hline Achievement of defined objective & ADO & Feedback from seniors & FD \\
\hline Attendance of Teachers & AT & Total quality Management & TQM \\
\hline Training and development & TD & Variance inflation factor & VIF \\
\hline
\end{tabular}




\section{Research Methodology}

Descriptive research is the type of research which explained the subject matter and don't give any judgment or interpretation. This research is also empirical in nature and the researchers have tried to investigate the relations hip between exogenous and endogenous variables as well. Researchers will try to verify the acceptance and rejection of the predefined research hypothesis. This research will provide the guidelines regarding the current subject matter/scenario.

\section{Data and Sample}

\subsection{Population}

The population of the research schoolwork was consisted of the following category of the respondents:

a) 70 Teachers working in Private colleges in Bahawalpur District Punjab.

b) 130 Teachers working in Public colleges in Bahawalpur District Punjab.

The main source of data was statistical cell of the Directorate of Public coaching (Colleges) Punjab from where entire list of private and public level colleges of Punjab were together, department of Statistics Government of the Punjab.

\subsection{Sample}

A sample is a little part of a population chosen for analysis and observation. For selecting the sample from the population the convenience sampling and simple random technique were used due to cost and time constraints over there.

\subsection{Research Instruments:}

The researchers prepared questionnaire and interviews on the basis of literature review is developed as instrument for collection of data. The questionnaire included of objects mostly about the performance evaluation of teachers in colleges. The questionnaire consisted of total 20 items having five constructs were based upon likert scale.

\subsection{Data collection}

Some other questionnaires were filled from colleges through their friend's research fellows and ex-colleagues. The researchers felt curious problems in getting the questionnaires filled in from teachers because the most of the time teachers were engaged in taking their classes. The response rate was 100 percent form teachers. Whole procedure of data collection from teachers was completed in one month.

\subsection{Data Analysis}

The responses attained through the above mention research elements were tabulated, analyzed and discussed with college teachers and experts. While analysis of the questionnaire responses was prioritized on the basis of frequency. The collected data were analyzed by using computer software's, named as Microsoft Excel 2007 and SPSS version 17.0. Following measures such as Cronbach's alpha, Regression and collinearity were used to analyze the data.

IV. Findings and Analysis

Table No.01 Demographic Variables Results

\begin{tabular}{|c|c|c|c|c|c|c|c|c|c|c|c|c|c|c|}
\hline \multicolumn{3}{|c|}{ Types of Institute } & \multicolumn{3}{|l|}{ Gender } & \multicolumn{3}{|c|}{ Qualification } & \multicolumn{3}{|c|}{ Age of Respondent } & \multicolumn{3}{|c|}{ Experience } \\
\hline Details & 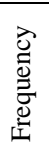 & $\begin{array}{l}\overrightarrow{0} \\
\text { 苞 } \\
\text { ص. }\end{array}$ & Category & 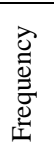 & 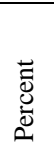 & Detail & 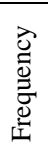 & $\begin{array}{l}\overrightarrow{\overline{0}} \\
\text { : } \\
\text { Q }\end{array}$ & $\begin{array}{l}\text { Categor } \\
\text { y }\end{array}$ & 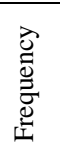 & 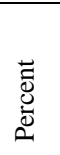 & Years & 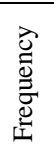 & $\begin{array}{l}\overrightarrow{0} \\
\text { D. } \\
\text { ص. }\end{array}$ \\
\hline Private & 17 & $\begin{array}{l}56.6 \\
7 \\
\end{array}$ & Male & 116 & 58 & Graduation & 35 & 17.5 & $21-30$ & 40 & 20 & $1-5$ & 25 & 12.5 \\
\hline Public & 13 & $\begin{array}{l}43.3 \\
3 \\
\end{array}$ & Female & 84 & 42 & Master & $\begin{array}{l}13 \\
5\end{array}$ & 67.5 & $31-40$ & 75 & 37.5 & $6-10$ & 40 & 20 \\
\hline & & & & & & M. Phil & 30 & 15 & $41-50$ & 45 & 22.5 & $11-15$ & 55 & 27.5 \\
\hline & & & & & & & & & $51-60$ & 40 & 20 & $16-20$ & 50 & 25 \\
\hline & & & & & & & & & & & & $21-25$ & 30 & 15 \\
\hline Total & 30 & 100 & & 200 & 100 & & $\begin{array}{l}20 \\
0\end{array}$ & 100 & & 200 & 100 & & 200 & 100 \\
\hline
\end{tabular}

\section{Description:}

In the above table 01 Researcher categorize the variables on the basis of demographic. There are five demographic variables types of institute, Gender, qualification, age of respondent and their experiences. 
Researcher collected the data from private sector and public sector colleges. There are 56.67 percent of private sector colleges and 43.33 percent public sector. Researcher categorized Gender into Male and Female Teachers of colleges with percentage of 58 and 42 respectively. Qualification of teachers categorized into three level, Graduates teachers percentage is 17.5, Master qualified teacher are 67.5 percent and M. Phil qualified teacher in public and private colleges is 15 percent. Researcher also categorized the age of teachers. There are different groups of ages such as 21-30 year exist twenty percent teachers, 31-40 year exist 37.5 percent, $41-50$ year exist 22.5 percent and 51-50 year exist twenty percent. The experience of the respondents were that 12.5 percent respondents having the experience falls between one to five years, 20 percent respondents having the experience six to ten years, 27.5 percent respondents having the experience eleven to fifteen years, 25 percent respondents having the experience sixteen to twenty years and 15 percent respondents having the experience of teaching twenty to twenty five years.

\section{Reliability Analysis}

Table No.02 Collinearity Results

\begin{tabular}{|ll|l|l|l|}
\hline & \multicolumn{2}{c|}{ Variables } & \multicolumn{2}{c|}{ Collinearity Statistics } \\
\cline { 4 - 5 } & \multicolumn{2}{|c|}{ Tolerance } & VIF \\
\hline ADO & $\longrightarrow$ & .592 & 1.45 \\
TD & $\longrightarrow$ & .319 & 3.11 \\
TT & $\longrightarrow$ & .369 & 2.71 \\
FS & $\longrightarrow$ & .621 & 1.21 \\
\hline
\end{tabular}

\section{Description;}

The researchers used multicollinearity to check the reliability of exogenous variables in this study. Two indicators named as Tolerance and VIF are used to evaluate the collinearity. The bench mark of VIF defined different researchers differently. Belsely (1991) used 5 as standard value for the VIF but our results show maximum value of VIF 3.78 which is low from the benchmark. Other researchers used VIF value 10 as benchmark. Therefore we conclude that there is no collinearity exists among these exogenous variables. This study found the minimum value of tolerance is .291 which is higher than the standard value of tolerance .20 and conclude that researchers can continue their research for regression analysis with full confidence.

\section{Regression Analysis}

Table No.03: Comprehensive Regression Results

\begin{tabular}{|c|c|c|c|c|c|c|c|c|c|c|}
\hline \multirow[t]{3}{*}{ Sr \# } & \multirow{3}{*}{\multicolumn{2}{|c|}{ Variables }} & \multicolumn{4}{|c|}{ Types } & \multirow[t]{3}{*}{ t. value } & \multirow[t]{3}{*}{ Beta } & \multirow[t]{3}{*}{ P-value } & \multirow[t]{3}{*}{ Status } \\
\hline & & & \multicolumn{2}{|c|}{$\begin{array}{l}\text { Private } \\
\text { colleges }\end{array}$} & \multicolumn{2}{|c|}{$\begin{array}{l}\begin{array}{l}\text { Public } \\
\text { colleges }\end{array} \\
\end{array}$} & & & & \\
\hline & & & 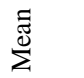 & คి & 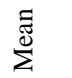 & $\stackrel{\rho}{\leftrightarrow}$ & & & & \\
\hline 1 & $\mathrm{ADO}$ & & 4.03 & $\begin{array}{c}.60 \\
0\end{array}$ & 4.08 & .604 & 4.612 & .697 & $\mathrm{P}<0.05$ & Accepted \\
\hline 2 & AT & & 4.08 & $\begin{array}{l}.86 \\
2\end{array}$ & 3.90 & $\begin{array}{c}1.11 \\
8\end{array}$ & 5.356 & .787 & $\mathrm{P}<0.05$ & Accepted \\
\hline 3 & TD & & 3.81 & $\begin{array}{c}.77 \\
6\end{array}$ & 3.79 & $\begin{array}{c}1.18 \\
0\end{array}$ & 3.420 & .611 & $\mathrm{P}<0.05$ & Accepted \\
\hline 4 & TT & & 3.51 & $\begin{array}{c}.96 \\
1\end{array}$ & 3.43 & .979 & 1.430 & .532 & $p>0.05$ & Rejected \\
\hline 5 & FS & & 3.86 & $\begin{array}{l}.94 \\
8\end{array}$ & 3.77 & .876 & 3.671 & .633 & $\mathrm{P}<0.05$ & Accepted \\
\hline
\end{tabular}

\section{Description;}

\section{Achievement of defined objective}

This study finds that p-value of this variable is less than 0.05 and t-value (4.612) is greater than 1.96 and Beta/coefficient that shows the positive and negative relationship of variables, here value is .697. Therefore we conclude that there is a significant positive correlation between ADO and PE and it have strong contribution during performance evaluation process. 


\section{Attendance of Teacher:}

According to this variable p-value is less than 0.05 and t-value (5.356) is greater than 1.96 and Coefficient/Beta gives the negative and positive relationship of variables and the value is .787. So this figure out that AT and PE are significant positively correlated. It also have great importance is measuring performance evaluation.

\section{Training and development:}

TD and its relationship towards PE is strongly positive correlated because the p-value is less than 0.05 and $t-$ value (3.420) is above than 1.96 and its Beta/coefficient is .611. In order to determine the significant level, this variable helpful to predict the performance appraisal.

\section{Transfer of Training:}

The relationship between TT and intention to PE in colleges has insignificant interrelated because the p-value is greater than 0.05, t-value (1.430) is also less than 1.96 and its Coefficient/Beta is .532. This result suggested that TT is not best factor while shaping process of evaluation.

\section{Feedback from Senior:}

Basically, FS and its relationship towards PE have significant positively linked between these two variables. In order to measuring affiliation p-value (3.671) is less than 0.05, t-value is greater than 1.96 and its Beta/coefficient .633 which provide the negatively and positivity of relations. So, it is recommended that FS is best predictor for determining the performance.

\section{Limitations of the study}

This reading is conduct in Punjab province of Pakistan. Therefore, the consequences of this study cannot be universal. These results can be generalized only in developing countries those have same cultural, educational, economic and environmental background likes Pakistan. This research data was collected from colleges therefore its results will be fruitful for evaluating the performance of teachers in colleges.

\section{Discussion and Conclusion}

The most important goal of the study was to examine the current performance appraisal system for teachers in colleges. Result of the study recommend several ways that head of educational departments and the college management should have to adapt in order to enhance the quality of this system and its impact on teacher's performance. Achievement of defined objectives, attendance of teachers, training and development, transfer of training and feedback from seniors can be the factor of performance evaluation and should all the time be measured, while developing a good performance appraisal method for teachers in colleges. Findings have shown that four variables such as ADO, AT, TD and FS have strongly positively linked with performance evaluation process but one variable named as TT transfer of training have negative impact on evaluating the performance. Those variables which have positive relationship with performance evaluation are best predictors of performance of the employees while the variable which has negative relationship with performance evaluation will not have much importance in this context. The role of administrative is important in evaluating teachers, developing their capabilities and getting good results from them. Therefore, administrative should also be trained enough for conducting performance evaluation of teachers according to their education systems.

Through the assessment process as practiced in colleges of Punjab teachers can gain increased facts and skills, which ultimately enhance their performance in their daily duties in the colleges. Most significantly, the appraisal process plays a vital role in molding the disposition of the teachers positively towards the teaching occupation. Many teachers do not understand the purposes or practice of the current teacher appraisal process due to lack of orientation and training. This constitutes an important and urgent path for in service teacher training. In sum, the current teacher evaluation system as practiced in colleges of Punjab is suitable, but managerial and training aspects should be improved. The teacher evaluation system should be periodically reviewed to keep it in line with change that may have taken place in the education system.

\section{References}

[1] Jahangir, F. S. Student Evaluation of Their Teachers' Performance. Pakistan Psychological Studies, 6(1): 27-30, (1988).

[2] Kim Marshall, Jossy Bass. The main idea is rethinking teacher's supervision and evaluation. (2009).

[3] Sadker, P. M. and D. M. Sadker. Teachers, School and Society. McGraw-Hill Inc., New York, USA, (1997). PP. 39-66.

[4] Iqbal, M. Misali Ustad, Sadar Mualeen aur Mualmeen ki Nazar Main. Master thesis, University of the Punjab, Lahore, Pakistan. P. 69, (1986).

[5] Darling-Hammond, L. How teacher education matters. Journal of Teacher Education. 51, 166-173, (2000).

[6] Cudzie Jazky Anglicitina. Effects of performance appraisal on employees attitude, (2004).

[7] Anderson, W. L. Increasing Teacher Effectiveness. UNESCO: International Institute for Educational Planning, Paris. Pp. 16, I8, (2004).

[8] Sarwar, Aslam, Rasheed. Hindering factors of teachers' high performance in higher education in Pakistan, Vol. 2, (2010).

[9] Beerens, S. G. Successful Teaching in Secondary Schools. Foresman and Company, Atlanta. p. 111-113, (2000).

[10] Helsel, R. A. et al. Teacher's perceptions of organizational climate and expectations of successful change. Journal of Experimental Education, 11(1): 58-87, (1969). 
[11] George, J. R. and L. D. Bishop. Relationship of organizational structure and teacher personality characteristics to organizational climate. Administrative Science Quarterly, 13(4): 211-310, (1971).

[12] Srivastava, R. (1985). A study of school effectiveness in relation to organizational climate. D.Phil. dissertation, Allahabad University, India.

[13] Casteed, D. Principal and Teachers Perceptions of Several Climate Related to Value Added Assessment and Relates School External Effects in the First Tennesse District. Dissertation Abstracts International Vo1.55, No.9, (1995).

[14] John, M. C. and Taylor, J. w., Leadership Style, School Climate, and the Institutional Commitment of Teachers. International Forum, 2(1): 25-57, (1999).

[15] Johnsrud, L. K., Heck, R. H., and Rosser, V. J. Morale matters: Midlevel Administrators and their intent to leave. Journal of Higher Education, 71: 34-59, (2000).

[16] Volkwein, J. F. and Y. Zhou. Testing a model of administrative job satisfaction. Research in Higher Education, 44(2): 149-171, (2003).

[17 ] Belsely, D.A . Conditioning Diagnostics: Collinearity and Weak Data in Regressions. Wiley, New York, 1991.

[18] Lower, M. Frame Factors. In M. J. Dankin (eds). (1987). 